Revista Iberoamericana, Vol. LXXX, Núm. 246, Enero-Marzo 2014, 19-30

\title{
CÓMO SE HACE UNA OBRA: ÉTICA Y GENÉTICA
}

POR

JACQUES NEEFS

Hoy en día, la atención crítica hacia los borradores de los escritores y hacia el proceso de confección de las obras literarias se ha desarrollado mucho. ${ }^{1}$ De cierto modo, esto cambia el paradigma que se estableció a fines del siglo dieciocho y en gran parte del diecinueve, a propósito del interés de lo que podemos llamar los "manuscritos de trabajo" de los autores. El interés ha sido históricamente variable a lo largo y ancho de los diferentes países y culturas.

Durante el Renacimiento y la Edad Clásica, la conservación deliberada de manuscritos, notas, esquemas, borradores y sucesivas ediciones que llevaban a una obra determinada era muy poco frecuente. Esto no significa que la convención de hacer variaciones en las obras no existiera, y Michel Jeanneret ha mostrado en su libro Perpetuum Mobile la importancia, durante el Renacimiento, de la variación de un texto cuando se imprimía de una edición a otra -y a veces, incluso dentro de una sola edición, ya que la obra se imprimía copia por copia. De este modo, Ronsard, por ejemplo, intervenía directamente "en lo del impresor". Éste también era el caso en el siglo dieciocho, con Rétif de la Bretonne. En el siglo dieciséis, Montaigne ofrece el que sin duda es el más llamativo ejemplo en sus Ensayos. De una edición a otra, amplía su libro a través de involuciones y adiciones (lo que él llama su “relleno”), agregando finalmente muchos textos nuevos en los márgenes de la última edición impresa (1588), de una manera espectacular, hasta su muerte. ${ }^{2}$

Sin embargo, es notable que el interés en el taller de trabajo de la obra literaria sea relativamente reciente en la historia, en tanto que éste no ha sido el caso en las artes

1 Para estudios recientes, ver Almuth Grésillon, La mise en æuvre. Itinéraires génétiques; Sally Bushell, Text as Process. Creative composition in Wordsworth, Tennyson and Dickinson; Daniel Ferrer, Logiques du brouillon. Modèles pour une critique génétique.

2 En lo que se llama "Exemplaire de Bordeaux", Bibliothèque municipal de Bordeaux. Ver Montaigne, Les Essais Reproduction typographique de l'Exemplaire annoté par l'auteur y Alain Legros, "Nous deux, mais c'était lui ou moi (Montaigne et/ou La Boétie)". 
plásticas: estudios, esbozos y versiones en borradores tanto de obras pictóricas como de esculturas han sido objeto de colección e interés desde el Renacimiento en particular. Pero en el caso de los manuscritos literarios, algunos importantes ejemplos sobresalen en esta historia. Goethe organizó sus propios “archivos del poeta y escritor” -es decir, archivos de su propia creación-y se ocupó de la edición completa de sus escritos, convencido de que esto era importante no sólo para sí mismo, sino que era un "proyecto trascendente para la literatura alemana en su totalidad” (Request for Privilege made to the Federal Diet of Germany, January 11, 1825). La preocupación aquí es profundamente filológica y patrimonial, así como autoral. Hay un ejemplo análogo en Francia con Victor Hugo, quien legó “todo lo que encontró escrito o dibujado por [su] mano" a la Bibliothèque Nationale de Francia por un codicilo a su testamento de 1881, y quien planeó con precisión la edición póstuma de sus obras completas, incluyendo un lugar para todos los fragmentos preparatorios, borradores y textos abandonados, que él llamaba su "pila de piedras”. Hay toda una historia muy interesante para contar acerca del cuidado -o falta de él- hacia los archivos de obras; es una historia que actualmente se está desarrollando en todos los lugares en los que hay interés por el trabajo con manuscritos y, por supuesto, donde sea que se preste especial atención a las colecciones. Esto no ocurre en todos los países a la misma velocidad, pero es seguro que el deseo de "conservar" aquellos rastros del trabajo es ahora una preocupación extendida.

Éste no siempre ha sido el caso para los autores mismos y hay muchos ejemplos de autores cuya voluntad es destruir los pedazos de sus obras incompletas - desde Chateaubriand con los borradores de su Mémoirs d'Outre-tombe a Mallarmé con su inconcluso Hérodiade o Kafka. Stendhal es un ejemplo relativamente paradójico de esto, ya que expresamente no guardó los manuscritos de su obra publicada; sin embargo, por otro lado, concibió y planeó por completo obras como, Lucien Leuwen y Henry Brulard, que permanecieron a la espera, en la inconclusión relativa del manuscrito en vistas a un remoto destino, en el caso de que quizá se publicara posteriormente. ${ }^{3}$ Hoy en día, la conservación de manuscritos se ha vuelto algo bastante común y en Francia los trabajos de autores vivos se coleccionan con regularidad, por ejemplo, en la Bibliothèque National, el IMEC (Institut de la mémoire de l'édition contemporaine), la Biblioteca Jacques Doucet o las bibliotecas de provincias -por ejemplo, Michel Butor ha donado sus manuscritos a la biblioteca de Niza.

Hay que hacer otro comentario preliminar. El interés en la abundancia de posibilidades de la que los dossiers genéticos dan muestra no puede, separarse de ninguna manera, de la tendencia estética moderna que concibe la obra como un objeto que lograr, antes que literalmente producir -la obra como una nueva intensidad estética que conquistar

3 Ver Béatrice Didier y Jacques Neefs, Écritures du romantisme. I Stendhal.

Revista Iberoamericana, Vol. LXXX, Núm. 246, Enero-Marzo 2014, $19-30$
ISSN 0034-9631 (Impreso)


antes que un objeto que se produce dentro de las reglas de un género. Vemos esto en Flaubert, por ejemplo, con el postulado de "una prosa ideal" o en Proust, quien integra la virtualidad del trabajo en la narración misma: éste es el libro por hacer, por escribir, esa ficción se ubica como si estuviera antepuesta. Esto dista mucho de la idea clásica de una obra completa, lograda, como un objeto de contemplación. El siglo veinte ha visto el desarrollo de la estética del cuaderno de notas, del fragmento (en particular, entre los poetas: René Char, Du Bouchet) y, en prosa narrativa, la estética del nuevo comienzo, el tartamudeo, la aproximación, como en Beckett, por ejemplo. Allí, la prosa está perfectamente construida para ser experimentada como jadeante, acercándose con ansiedad a lo insostenible, a lo inefable; es una especie de repetido intento de enunciar; un "borrador" notablemente organizado para una dicción más intensa. El trabajo se concibe como el intento en funcionamiento, al mismo tiempo que un intento de hablar, de perdurar, de no desaparecer. Ponge llevó esta práctica al extremo, al punto de publicar sus intentos de poemas en La Fabrique du pré, a modo de juego, para la colección "Sentiers de la creation" ["Senderos de la creación"]. Esto, desde los años sesenta y setenta, marca de hecho una fecha la atención estética que se le da a partir de entonces a "los senderos de la obra", a la obra como proceso. También puedo mencionar a Arno Schmidt, quien publicó L'École des Athées, como un texto mecanoscrito, con dispositivos que acompañaban las páginas, como un montaje en proceso.

Hay, sin embargo, una cierta paradoja en el hecho de concentrarse precisamente en aquello que no se ha conservado, en lo que ha tenido que ser atravesado, desplazado o tachado, para que una obra apareciera tal como apareció. Los borradores son, en cierta manera, un residuo. En René Char and His Poems, Paul Veyne presenta al poeta diciendo:

La poesía se mueve; no es lo mismo de una vez a otra -no porque cambie, sino porque necesita nuevos horizontes y porque hay un territorio ilimitado para descubrir. Esta manada itinerante deja atrás los restos de los objetos de los que se ha nutrido: es decir, sus borradores, correcciones y variaciones; la anecdótica historia secreta de sus poemas e ideas más o menos adecuadas que lo ayudaron. En suma, las partes muertas de la escritura. $^{5}$

Pero, inversamente, los manuscritos de trabajo son el lugar mismo de esos desplazamientos que hacen el movimiento de la literatura y su transformación. Los borradores son el lugar donde las posibilidades se intentan, se descartan, se logran;

4 Ver también Comment une figue de paroles et pourquoi, donde Ponge publica todos los borradores de su poema "La figue", antes publicados en Tel Quel en 1960.

5 Citado en Paul Veyne, Le Quotidien et l'intéressant, Entretiens avec Catherine Darbo-Peschanski, Les Belles-Lettres, 1995, XIII, nota 1. René Char, « Moulin premier » XVII and « Auxiliaires ».

$\begin{array}{llllll}\text { Revista Iberoamericana, Vol. LXXX, Núm. 246, Enero-Marzo 2014, } & 19-30 \\ \text { ISSN 0034-9631 (Impreso) }\end{array}$ 
donde están las formas buscadas, acercadas y encontradas. Matisse lo pone así: “Cuando llevo a cabo mis dibujos, el dibujo que hace mi lápiz en la hoja de papel es parcialmente análogo al gesto de un hombre buscando su camino a tientas en la oscuridad”.

Los actos de invención del escritor, sus revisiones y decisiones, son completamente análogos a esto y podemos agruparlos en tres tipos principales. Primero, está todo lo que entra bajo la categoría de "notas”, ya sea documentación, observación, recuerdos o ideas para desarrollar; segundo, lo que está comprendido en la categoría de concepción de la totalidad de una obra, su plan; la idea activa que es la composición -la elaboración de escenarios y esbozos; la organización de una estructura o el desarrollo de un sistema de restricciones (pienso aquí en el extraordinario sistema de Perec para La Vie mode d'emploi [La vida instrucciones de uso]). ${ }^{6}$ Finalmente, está lo que se comprende bajo la categoría del escribir propiamente dicho -reescritura, correcciones y el punto final de un texto, si es que llega. De hecho, lo "incompleto" tiene un lugar considerable en las reflexiones genéticas, tal como lo tiene en toda producción literaria, e indudablemente eso constituye una de las cuestiones más interesantes a propósito de la definición de qué es lo que hace una obra.

De este modo, podemos considerar que la atracción de una obra tiene dos caras: el espectador o lector lleva a cabo los efectos de la obra, el poder de complejidad que la caracteriza, su "voluntad", una palabra que Baudelaire usa varias veces para designar la fuerza y atracción de una obra.

Lo que Diderot amaba en la pintura era el momento en el que algo se busca:

¿Por qué el dibujo bello nos atrae más que una pintura bella? Es porque hay más vida y menos forma en él. Cuando uno introduce formas, la vida desaparece [...] Quizá el dibujo sólo nos atrae con tanta fuerza porque, siendo indeterminado, le permite más libertad a nuestra imaginación, que ve en él cualquier cosa. Es como los niños mirando las nubes y todos somos más o menos niños. Es como la música vocal y la música instrumental; escuchamos lo que aquella dice, hacemos que ésta diga lo que queremos que diga. (247, nuestra traducción)

La impresión invisible o legible que deja una obra de arte vuelve a señalar hacia los movimientos inscritos dentro de ella, al trabajo que se hizo allí; al arte que desarrolló esta forma única; a las hondas, profundas combinaciones que aparecen en la superficie como estructuras reconocibles. La relación que tenemos con una obra de arte es, de cierto modo, profundamente mimética -en el sentido de que, como ha enfatizado Paul Klee, la obra ofrece múltiples sendas a la mirada o, en el caso de las obras legibles,

6 Ver Georges Perec, Le Cahier des charges de La Vie mode d'emploi, transcripción y presentación de Hans Hartje, Bernard Magné, Jacques Neefs.

$\begin{array}{llllll}\text { ISSN 0034-9631 (Impreso) } & \text { ISSN 2154-4794 (Electrónico) }\end{array}$ 
múltiples signos, configuraciones, proposiciones y recordatorios para la comprensión y la memoria. La relación que tenemos con una obra de arte es de cierto modo mimética de los movimientos que le dieron forma, al punto de que la imaginación se apropia de la tensión de la obra misma, y lo hace de modo que la información que tenemos de una obra "apoye la idea” que emite. El planeamiento que preside la elaboración de la obra tiene una honda influencia en su inteligibilidad y en su ejecución - en el sentido musicalpor parte de los lectores o espectadores. El destino de las formas estéticas depende de este doble aspecto. La atención que uno puede prestarles es como una recuperación de los gestos invisibles que le dan su complejidad e intensidad.

Tomemos la descripción de la pintura de Chardin de los hermanos Goncourt:

Pero si él no mezcla sus colores, los conecta; los ensambla, los corrige; los acaricia con un trabajo sistemático de reflexiones que, mientras deja intacta la franqueza de sus tonos compuestos, parece cubrir cada cosa con el color y la luz de todo lo que tiene cerca. A los objetos pintados de cualquier color, siempre les agrega algún tono, algún vívido color de los objetos que lo rodean. Cuando uno mira con atención, hay algo de rojo en este vaso de agua; rojo en este mantel azul, azul en esta sábana blanca. De aquí -de estos recordatorios y ecos continuos, la armonía de todo lo que pinta surge a la distancia; no la empobrecida armonía que surge lamentablemente de la fuente de tono, sino la gran armonía de consonancias que brota sólo de las manos de los maestros. (186-87)

Aquí, describir la obra de arte es detectar y comprender los entrelazados que resultan del trabajo del artista; es leer la pintura por medio de la identificación de los gestos colocados allí, es decir, los gestos que la han compuesto, que han creado su marco y nueva armonía. La pintura de Chardin ejerce atracción a través del trabajo que es tanto visible como disuelto dentro de la pintura; a través de lo que emerge en los mismos movimientos del pintor, luchando con los colores: "los conecta; los ensambla, los corrige; los acaricia con un trabajo sistemático de reflexiones”. Los Goncourt habían comentado anteriormente sobre la excepcionalidad del trabajo de Chardin y la curiosidad que provocó incluso mientras vivía:

La pintura de Chardin, su novedad, su originalidad, su personalidad, pre-ocupó en gran medida a sus contemporáneos. La curiosidad de éstos fue frustrada por aquellos procedimientos únicos, por esa inexplicable representación de la naturaleza, este milagro de imitación artística [...]. Se maravillaban e intentaban averiguar por la trituración de su impasto, su mezcla de los colores, la cocina de su pintura. Le preguntaban por sus recetas para los colores, el lado oculto de su talento. Se quejaban de no conocer a nadie que lo hubiera visto pintar. (186-87)

\begin{tabular}{l} 
Revista Iberoamericana, Vol. LXXX, Núm. 246, Enero-Marzo 2014, $19-30$ \\
\hline ISSN 0034-9631 (Impreso)
\end{tabular} 
Diderot comenta acertadamente sobre este enigmático poder de la pintura de Chardin a propósito de Raie dépuillée: ${ }^{7}$

\begin{abstract}
Uno no puede entender esta magia. Hay gruesas capas de color aplicadas una sobre otra, el efecto de lo cual transpira desde abajo hacia la superficie. En otras ocasiones, uno pensaría que se ha soplado un vapor en el lienzo; en otro lugar, que se ha lanzado una espuma sobre él. Rubens, Berghem, Greuze, Loutherbourg podían explicar esto mejor que yo; todos ellos hacían que sintieras su efecto en los ojos. Acércate al lienzo y todo se vuelve borroso; aléjate y todo se re-crea y se re-produce a sí mismo. Alguien me dijo que cuando Greuze entraba a la sala, al ver la obra de Chardin que acabo de describir, la miraba y pasaba, suspirando profundamente. Su elogio es más breve y vale más que el mío. (194-95)
\end{abstract}

Sin embargo, es insuficiente pensar que el secreto del estilo de Chardin puede haber estado contenido en una técnica, en una cocina, y los Goncourt describen con curiosa pasión lo que debe haber sido la concentración del pintor:

Lo que Chardin quería esconder cuando no dejaba que nadie se acercara a su caballete cuando estaba pintando no eran procedimientos misteriosos, sino simplemente su búsqueda a tientas, el doloroso esfuerzo y el difícil nacimiento de sus obras. [...] Era lento para encontrar, para producir y para terminar una obra. Al mirar sus obras menos fatigadas, uno siente mañanas ansiosas y laboriosas, mañanas de luchas con un modelo o con la naturaleza, durante las que el pintor corregía, borraba, permanecía en su lugar, esforzando los ojos y la mente, como una mano dudando sobre las cuerdas, hasta un momento de iluminación, un minuto, un destello: entonces, de repente, el día se abría dentro de él, descubría su pintura, por debajo, los esbozos perdidos de otros dos o tres. (134-36)

“Mirando sus pinturas, uno se pregunta...”: una parte de la atracción de las obras de Chardin, de su profundo efecto, viene del sentimiento que uno puede tener a partir del pensamiento concentrado que se exhibe en ellas, ejercido con intensidad, al punto del logro y el éxito.

La perspectiva “genética” del trabajo de una obra está, en gran medida, gobernada por esta atracción. El interés de atrapar un atisbo de la “cocina” del artista no está ausente, sin duda, de la indagación "genética” y es interesante concentrarse en "métodos” y en “técnicas” -en la manera en la que un grupo particular de obras se desarrolla. Pero lo que principalmente está en juego en semejante visión del movimiento de creación es lo que nos permite entender a propósito del desarrollo de un estilo, una visión; lo que

7 Esta pintura ha sido comentada con frecuencia: ver, por ejemplo, Proust, Esquisse LVII, À l'ombre des jeunes filles en fleurs, La Recherche du temps perdu.

$\begin{array}{llllll}\text { ISSN 0034-9631 (Impreso) } & \text { ISSN 2154-4794 (Electrónico) }\end{array}$ 
encuentra, dentro de la obra del escritor, que es el interés de la obra y de su contenido estético.

La improvisación de Stendhal puede sentirse a la perfección en la velocidad específica de sus novelas, así como en sus textos encontramos el arte de la elipsis y del entrelazado de voces narrativas con la pasión de la acción; la obra de la distancia y la intimidad que expone las emociones de los personajes al punto de lo inefable y la aparente brusquedad de los desenlaces (o de la falta de desenlace) y la silenciosa disipación de la emoción y del deseo en la escritura. Sin embargo, el estudio "genético" de los manuscritos de Stendhal que quedan ${ }^{8}$ refuerza considerablemente -quizá más de lo que lo explica- este sentimiento estético. En las páginas manuscritas de Stendhal uno puede leer el movimiento de la escritura, la tensión que corre junto al curso de la narración, hacia la forma de la obra, y uno percibe, como si fuera algo material, la velocidad de la escritura. Stendhal registró el ritmo al que componía, como en esta nota al margen del manuscrito para Lucien Leuwen: "15 de diciembre. 1 hora 3/4 desde el mediodía hasta 1:45 16 páginas -y otra vez, mientras miro el reloj porque vamos a la Villa Ludovisi. 16 páginas en 125 minutos”. Enfatiza en el manuscrito mismo su incapacidad para construir una línea argumental de la obra, como en esta otra nota marginal de Lucien Leuwen: "En mí. Dominique [uno de los tantos nombres que Stendhal se daba a sí mismo en los manuscritos] arma el esbozo mientras avanza y a menudo, después de la historia, porque le trae algo a la memoria que le destruye el corazón” y el escritor se apoya completamente en el llamado del trabajo mismo: "Línea argumental. La niebla se levantará mientras avance en la línea argumental. Veo el próximo capítulo,” (Feder 353, nuestra traducción). El trabajo preparatorio para el libro se inclina inmediatamente hacia la tonalidad del libro y a su dicción.

El análisis "genético" se concentra en el umbral de proximidad e inversión entre la idea de la obra tal como se realiza en la escritura y la consistencia y estabilidad que la obra misma conquista en su propia autonomía y existencia.

De alguna manera, la densidad de la prosa de Flaubert, tan nueva en su época, la complejidad increíblemente tangible de una prosa “abarrotada”, tal como él dijo; debajo de su carácter aparentemente límpido, se encuentra el “mosaico” de composición de sus novelas, tal como lo puso Nabokov, a través de sucesivos desplazamientos asociativos, a través del sutil entrelazado temático que crea las brillantes reflexiones de los textos, como Jean-Pierre Richard lo describió tan bien en Littérature et sensation, y que crea la particular tensión de esta escritura-perfectamente legible y palpable en el texto publicado.

Sin embargo, estudiar los manuscritos de Flaubert es bucear contra la corriente de su complejidad, en el trabajo mismo de sus construcciones rítmicas y temáticas -el

8 Ver Jacques Neefs, "Stendhal, sans fins”. Ver también Henry Brulard, editado por Gérald Rannaud, edición facsimilar y transcripción, con un importante prefacio.

$\begin{array}{llllll}\text { Revista Iberoamericana, Vol. LXXX, Núm. 246, Enero-Marzo 2014, } & 19-30 \\ \text { ISSN 0034-9631 (Impreso) }\end{array}$ 
trabajo "prosódico" propiamente dicho que constituye el estilo de Flaubert. Uno de los aspectos más sorprendentes es la extensión de la preparación de escenarios, así como el trabajo de notas preparatorias que tomaba incluyendo las notas de lectura (al contrario de Stendhal). Dehecho, Flaubert componía varios escenarios y líneas argumentales sucesivos, a lo largo de su vasta, enciclopédica investigación documental antes de comenzar lo que llamaba la "escritura" de su novela. ${ }^{9}$ El momento de preparar la documentación y las líneas argumentales -el momento de desarrollar el "sujeto"- tiene una función muy particular para Flaubert: es la condición de posibilidad de la "escritura" misma. El espacio entre estos dos momentos corresponde precisamente a la relación entre la idea de la obra y la transformación estética del lenguaje; entre la idea del libro y su inscripción en una prosa capaz de soportar, en cada uno de sus puntos, el efecto completo de la obra. Flaubert indicó esto en una carta a Louise Colet cuando estaba componiendo Madame Bovary, a propósito de las correcciones de lo que ya estaba escrito: "Para las correcciones, antes de hacer una sola, re-contemplo el todo. -Y me esfuerzo sobre todo por mejorarlo, no cortando sino creando de nuevo. Todas las correcciones tienen que hacerse de este modo. Uno debe reflexionar sobre su propio objetivo antes de pensar en la forma, porque sólo resulta bien si la ilusión del sujeto nos obsesiona” (carta a Louise Colet, 29 de noviembre de 1853, nuestra traducción). La intensa concepción del "sujeto" es imperativa aquí, para obtener la precisión de la prosa: "No veo mi objetivo claramente. Para que un libro transpire verdad, tiene que estar relleno de su sujeto hasta las orejas. Luego, el color llega con completa naturalidad, como un resultado fatal, como el florecimiento de la idea misma" (carta a Ernest Feydeau, 6 de agosto de 1857, nuestra traducción). Aquí, podemos pensar en Chardin según los Goncourt, en ese momento en el que "descubría su pintura, por debajo, los esbozos perdidos de otros dos o tres".

Finalmente, el ejemplo de Balzac es igualmente iluminador acerca de la relación que la investigación genética puede cultivar con la interpretación estética de una obra. El móvil que Balzac construye con La comedia humana puede leerse como una obra con múltiples entradas, ya que las novelas exceden el marco clasificatorio ordenado que los divide en Estudio de costumbres, Estudios filosóficos y Estudios fisiológicos, y la circulación dentro de la totalidad de La comedia humana es una gran parte de su fuerza y significado. Este conjunto es el resultado de una inmensa obra de desarrollo gradual, extendiéndose hacia el horizonte de una totalización improbable; un trabajo de redistribución y adaptación, como la edición de la Pléiade de la obra de Balzac, bajo la dirección de P. G. Castex, bien lo muestra, y que Stéphane Vachon demuestra meticulosamente en "Les Travaux et les jours" d'Honoré de Balzac: chronologie de la création balzacienne. El movimiento de la obra misma, el sorprendente trabajo de ajustes y las variaciones de las perspectivas que Balzac desarrolló en ese momento, es

9 Ver Plans et scénarios de Madame Bovary, editado por Yvan Leclerc.

$\begin{array}{llllll}\text { ISSN 0034-9631 (Impreso) } & \text { ISSN 2154-4794 (Electrónico) }\end{array}$


una fórmula poderosa porque le da fuerza y precisión a su representación de un mundo que desde ese momento estaba constituido por un nuevo tipo de movilidad social, porque crea una ciencia de "diferencias ínfimas", que "se agitan" en el drama moderno. El desarrollo de una obra tanto múltiple como unificada es una respuesta estética al examen de nuevas formas de redistribución social en una sociedad de igualdad democrática. Una vez más aquí, las modalidades del desarrollo de la obra inventan precisamente el espacio y el movimiento que le da a esta obra su forma única, su organización y significado.

El contraste entre estos tres escritores cercanos a la época del "gran realismo" bosqueja varias formas de lo que es posible. La génesis de una obra es como si estuviera constituida orgánicamente de acuerdo con un imperativo estético y significante que la determina. La perspectiva genética le permite así a uno entender el trabajo de desarrollar un texto como constitutivo, estrictamente, de una dimensión estética propia a la obra. $\mathrm{Si}$, por ejemplo, sobre la base de los tres ejemplos dados aquí, uno se concentra en el desarrollo de la prosa narrativa de la ficción, uno puede reconocer un contraste entre las obras con un fuerte planeamiento formal, con tiempo dedicado a la deliberación y desarrollo de un escenario, una línea argumental, una estructura; y, por el otro lado, obras para las cuales su dicción es primordial y que encuentran su intensidad en el curso de la escritura misma, que parece llamado por lo que descubre adelantado a sí mismo. “A cada página veo la niebla cubriendo el próximo impulso”, escribe Stendhal (manuscrito de Lamiel, Bibliothèque municipale de Grenoble, R 298, t. II, f $\mathrm{f}^{\circ}$ 70, $\mathrm{v}^{\circ}$ ). Esta oposición permite sin duda que uno distinga entre tipos de obras y tipos de dicción. Sin embargo, la fórmula siempre es adaptada con precisión al objetivo específico de la forma y la escritura.

Georges Perec, por ejemplo, como he dicho antes, asumió hasta el extremo la práctica de desarrollo formal previo a la narración y la escritura-con La Vie mode d'emploi, se dio a sí mismo una lista muy compleja de restricciones con las que cumplir: la espectacular estructura de la ficción, la forma del libro todo, la organización y extensión de los capítulos y personajes, objetos y detalles, están determinados por un sistema de organización muy riguroso y planeado. El sistema formal que usa es, de este modo, él mismo constitutivo de la estética y el sentido de la obra, creando un universo de "mónadas" que existen separadas y juntas; fragmentos de vida reunidos en su proximidad rota, sus destinos constreñidos, agotamiento de mundos. Y, simultáneamente, la escritura de cada capítulo obedece a una invención que requiere un trabajo de memoria considerable, una especie de conjunción secreta entre un capítulo y el siguiente, cuya aparente neutralidad de la escritura refuerza. Como en Balzac, la elaboración de la obra es la proyección de un vasto móvil que no puede totalizarse, como si estuviera congelado en una conjunción imposible. El papel de la génesis de la obra es mantener, dentro de la escritura misma, la dimensión de la memoria que ha de prevalecer sobre la dispersión radical.

\footnotetext{
Revista Iberoamericana, Vol. LXXX, Núm. 246, Enero-Marzo 2014, 19-30 
Del mismo modo, dentro del preciso marco de Le Temps retrouvé, Proust nunca paró de re-escribir el texto (“Todo está escrito pero todo ha de ser re-escrito”, escribió en 1913, Correspondance 367), agregándole constantemente, volviendo a relaciones internas distantes, múltiples, en un movimiento de metáfora incorporada que el trabajo en sí mismo teoriza. El vasto círculo de La Recherche encierra la escritura misma, la cual se vuelve infinita dentro del espacio mismo que ha creado. Leer los borradores de Proust, sus notas, es explorar el campo de una invención que lo reprime, descubre y rechaza para que entonces todo encaje en una estética interna, íntimas relaciones que crean el inmenso volumen de la difusa memoria que es la obra misma.

De este modo, en la consideración del trabajo de la obra, la perspectiva genética se concentra en las transformaciones internas de la forma y en la forma que toma esa transformación. Ésta hace posible que "varíe" nuestro punto de vista acerca de la invención de una forma, dentro de su movimiento, dentro de sus ajustes y renuncias, en sus dubitaciones y descubrimientos. En este sentido es perfectamente contemporáneo con una visión moderna de la estética como el movimiento de una obra, como he mencionado: la obra se compone de estratos provisorios y sucesivos. Matisse tomaba fotos de diferentes estados de sus pinturas. ${ }^{10}$ Envió una extensa serie de las etapas intermedias del "Grand nu rose" a sus clientes, las hermanas Cone en Baltimore, como si quisiera mantenerlas al corriente de las etapas de su construcción y darles a entender lo que estaba buscando con aquella pintura, con la idea que la pintura revelaría como resultado de aquellos estados, con la expectación del momento en el que, como para Chardin según los Goncourt, llega la "iluminación”, cuando la pintura "se descubre”.

Este momento no siempre llega, como demuestran ampliamente los archivos de la creación de una obra. Sin embargo, siempre está la tensión de una invención que se percibe allí, palpable, y los lugares de construcción que los estudios genéticos exploran se dan a sí mismos las maneras necesarias para inaugurar una estética única, específica de cada vez.

La interpretación genética tiene valor heurístico y de hecho constituye una reflexión crítica que pertenece al espacio “lateral” de la creación-el espacio de la obra buscándose a sí misma, aunque no sea, no obstante, la obra en sí misma. El comentario de Joan Miró en uno de sus “Cuadernos catalanes" expresa esto: "Proceso para crear esta obra: permanecer en contemplación frente a este lienzo vacío y hacer varios dibujos en hojas de papel” (78). El lienzo vacío, por su parte, pertenece al pintor solo.

Traducción de María Julia Rossi

${ }_{10}$ Ver Pierre Scheider, Matisse.

$\begin{array}{llllll}\text { ISSN 0034-9631 (Impreso) } & \text { ISSN 2154-4794 (Electrónico) }\end{array}$


OBRAs CITADAS

Bushell, Sally. Text as Process. Creative Composition in Wordsworth, Tennyson and Dickinson. Charlottesville: U of Virginia P, 2009.

Crouzet, Michel. Romans abandonnés. U.G.E. 10/18, 1968.

Diderot, Denis. Ecrits sur l'art et les artistes. Jean Starobinski, comp. París, Hermann, 2007.

Didier, Béatrice y Jacques Neefs. "Écritures du romantisme”. I Stendhal. Saint-Denis: Presses Universitaires de Vincennes, 1989.

Ferrer, Daniel. Logiques du brouillon. Modèles pour une critique génétique. París: Seuil, 2011.

Goncourt, L'Art du XVIIIème siècle, «Chardin», Euvres complètes, I, III, Slatkine Reprints.

Grésillon, Almuth. La Mise en œuvre. Itinéraires génétiques. París: CNRS Éditions, 2008.

Herschberg Pierrot, Anne. "Les Notes de Proust”. Génésis 6. París: Jean-Michel Place, 1994.

Jeanneret, Michel. Perpetuum Mobile. Métamorphoses des corps et des œuvres, de Vinci à Montaigne. París: Macula, 2000.

Legros, Alain. “Nous deux, mais c'était lui ou moi (Montaigne et/ou La Boétie)”. Genesis 29. Éditions des Archives Contemporaines (2008): 159-64.

"Les Travaux et les jours" d'Honoré de Balzac: chronologie de la création balzacienne. Presses Universitaires de Vincennes, Presses du CNRS, Presses de l'Université de Montréal, 1992.

Manuscript of Lamiel, Bibliothèque municipale de Grenoble, R 298, t. II, f $\mathrm{f}^{\circ} 70, \mathrm{v}^{\circ}$.

Miró, Joan. Carnets catalans (Carnet orange, 1940-1941). Ginebra: Éditions Albert Skira, 1976, t. II.

Montaigne, Michel de. Les Essais: Reproduction typographique de l'exemplaire annoté par l'auteur. [1913]. París: Imprimerie Nationale, 1906.

Neefs, Jacques. "Stendhal, sans fins”. Le Manuscrit inachevé. París: CNRS, 1986.

Perec, Georges. Le Cahier des charges de La Vie mode d'emploi. Hans Hartje, Bernard Magné, Jacques Neefs, transcr. y present. París: CNRS Éditions y Zulma, 1993.

Plans et scénarios de Madame Bovary. Yvan Leclerc, ed. París: CNRS Editions et Zulma, 1995.

Ponge, Francis. Comment une figue de paroles et pourquoi. París: Flammarion, 1977. La Fabrique du pré. Ginebra: Skira, 1971.

Proust, Esquisse LVII, À l'ombre des jeunes filles en fleurs, La Recherche du temps perdu. París: Gallimard, La Pléiade, 1987.

Richard, Jean-Pierre. Littérature et sensation. 1953. París: Seuil, 1990.

Schneider, Pierre. Matisse. París: Flammarion, 1993.

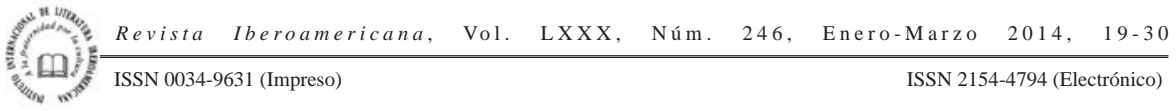


Stendhal. Henry Brulard. Gérald Rannaud, ed. y transc. París: Klincksieck, 1996-1997. Veyne, Paul. Le Quotidien et l'intéressant. Entretiens avec Catherine Darbo-Peschanski.

París: Les Belles-Lettres, 1995

$\begin{array}{lllll}\text { Revista Iberoamericana, Vol. LXXX, Núm. 246, } & \text { Enero-Marzo 2014, } 19-30 \\ \text { ISSN 0034-9631 (Impreso) }\end{array}$ 